\title{
A Study about the Temporal Constraints on the Martian Yardangs' Development in Medusae Fossae Formation
}

\author{
Jia Liu ${ }^{1,2}\left(\right.$, Zongyu Yue ${ }^{1,3, *}$, Kaichang Di ${ }^{1,3}\left(\mathbb{D}\right.$, Sheng Gou ${ }^{1,4}$ and Shengli Niu ${ }^{4}(\mathbb{C}$ \\ 1 State Key Laboratory of Remote Sensing Science, Aerospace Information Research Institute, \\ Chinese Academy of Sciences, Beijing 100101, China; liujia@aircas.ac.cn (J.L.); dikc@radi.ac.cn (K.D.); \\ gousheng@aircas.ac.cn (S.G.) \\ 2 University of Chinese Academy of Sciences, Beijing 100049, China \\ 3 CAS Center for Excellence in Comparative Planetology, Hefei 230026, China \\ 4 State Key Laboratory of Lunar and Planetary Sciences, Macau University of Science and Technology, \\ Macau 999078, China; 1909853ese30001@student.must.edu.mo \\ * Correspondence: yuezy@radi.ac.cn; Tel.: +86-10-64889553
}

Citation: Liu, J.; Yue, Z.; Di, K.; Gou, S.; Niu, S. A Study about the Temporal Constraints on the Martian Yardangs' Development in Medusae Fossae Formation. Remote Sens. 2021, 13, 1316. https://doi.org/10.3390/ rs13071316

Academic Editor: Kjartan Kinch

Received: 20 January 2021

Accepted: 19 March 2021

Published: 30 March 2021

Publisher's Note: MDPI stays neutral with regard to jurisdictional claims in published maps and institutional affiliations.

Copyright: () 2021 by the authors. Licensee MDPI, Basel, Switzerland. This article is an open access article distributed under the terms and conditions of the Creative Commons Attribution (CC BY) license (https:// creativecommons.org/licenses/by/ $4.0 /)$.

\begin{abstract}
The age of Mars yardangs is significant in studying their development and the evolution of paleoclimate conditions. For planetary surface or landforms, a common method for dating is based on the frequency and size distribution of all the superposed craters after they are formed. However, there is usually a long duration for the yardangs' formation, and they will alter the superposed craters, making it impossible to give a reliable dating result with the method. An indirect method by analyzing the ages of the superposed layered ejecta was devised in the research. First, the layered ejecta that are superposed on and not altered by the yardangs are identified and mapped. Then, the ages of the layered ejecta are derived according to the crater frequency and size distribution on them. These ages indicate that the yardangs ceased development by these times, and the ages are valuable for studying the evolution of the yardangs. This indirect dating method was applied to the areas of Martian yardangs in the Medusae Fossae Formation (MFF). The ages of the selected six layered ejecta range from $\sim 0.50 \mathrm{Ga}$ to $\sim 1.5 \mathrm{Ga}$, indicating that the evolution of the corresponding yardangs had been ceased before these times. Analysis of more layered ejecta craters and superposed yardangs implies that yardangs in the MFF have a long history of development and some yardangs are still in active development.
\end{abstract}

Keywords: Martian yardangs; age; layered ejecta crater

\section{Introduction}

Mars has a variety of aeolian landforms [1-6], and a yardang is an important example. Yardangs are widely distributed on the Martian surface, and it is significant for studying the Martian history of surface processes [7]. There have been many studies on their topography, distribution, and significance related to the past wind process [1,3,8-13]. For example, yardangs on Mars have been used as paleoenvironmental markers because the orientations of Martian yardangs are congruent with that of present-day bedform migration [14]. It has also been observed that Martian yardangs are dominated in N-S trend in equatorial regions, which is consistent with the orientation of the near-surface Hadley cell across the equator $[7,13]$. However, due to the lack of suitable methods and data sets, the chronology of Martian yardangs was rarely studied, although it is extremely important to the related analysis, such as the environmental evolution of the Martian surface [5,14].

The study of the formation age of yardang landforms is a basis to estimate the wind erosion rate in the yardang regions, and it is also a prerequisite to study yardang development processes in relation to the environment [15]. However, because its formation usually has a long duration, it is inconvenient to determine the yardang's age even on the Earth [15-17]. To date Earth yardangs, there are traditionally four methods: determining 
the ages of its top and bottom, analyzing the yardangs' erosion rate, inferring the relics of ancient activities, and correlating sediment and climatic change [17]. Generally, these methods will tentatively give the duration of the yardangs' formation, and these methods cannot be directly used in determining the ages of Martian yardangs.

The crater frequency and size distribution (CFSD) [18-26] method has been widely used in dating planetary surfaces. The rationale of the approach is to fit the observed crater size-frequency distribution of a counting area that represents the geologic unit to a known crater production function (PF) (e.g., [20,22]), which is further used to derive the absolute model age (AMA) along with a chronology function (CF) calibrated to radiometric dating from lunar samples [27]. The method has been expanded to date the surface of Mars by analyzing the differences in cratering rate, impact velocity, and target properties between them [28-31]. With the CFSD method, a series of Martian events and the boundaries between geological epochs have been dated [32-34]. The CFSD method was mostly used in the depositional terrain [18], while it was seldom used for erosional landforms such as yardangs. This is probably because the erosional landforms are usually formed within a long history, during which the superposed craters could be removed, and consequently, the dating results would be unreliable. As a result, yardangs are rarely dated with the CFSD method. However, according to previous studies [7], yardangs are mainly distributed in Martian equatorial regions [1,7], and many of them are closely related to layered ejecta craters [19]. Therefore, the ages of Martian yardangs can be constrained by dating the superposed layered ejecta craters with the CFSD method.

Layered ejecta craters are a kind of particular craters in the Martian surface that have been observed in images from Viking, Thermal Emission Imaging System (THEMIS), High Resolution Imaging Science Experiment (HiRISE), and Context Camera (CTX) missions [2,19,35-39]. The lobate deposits surrounding the crater are named layered ejecta $[1,2,40-43]$. Layered ejecta craters on Mars may have existed for a long history of Mars [43,44], and most studies indicate that their formation is related to volatile-rich targets [41,43]. The layered ejecta craters are distributed in a much wider range than other craters with similar diameters [45], which provides the feasibility for dating with the CFSD method.

This study focuses on constraining the ages of Martian yardangs in the Medusae Fossae Formation (MFF). Yardangs in this area are distributed near the equator of Mars and along the highland-lowland dichotomy boundary [46,47]. We use the stratigraphic relationship between adjacent ejecta faces and yardangs (Figure 1) to constrain the relative age of the yardangs, and then use the age of the ejecta from the CFSD method to constrain the ejecta's approximate absolute age. Thus, the age of the yardangs can be constrained by the layered ejecta, and the age of the latter can be determined with the size-frequency distribution of the superposed craters with the CFSD method. Subsequently, the development of the yardangs can be analyzed. The constraint of the formation time of Martian yardangs can provide important information on the paleoenvironment and paleoclimate. 

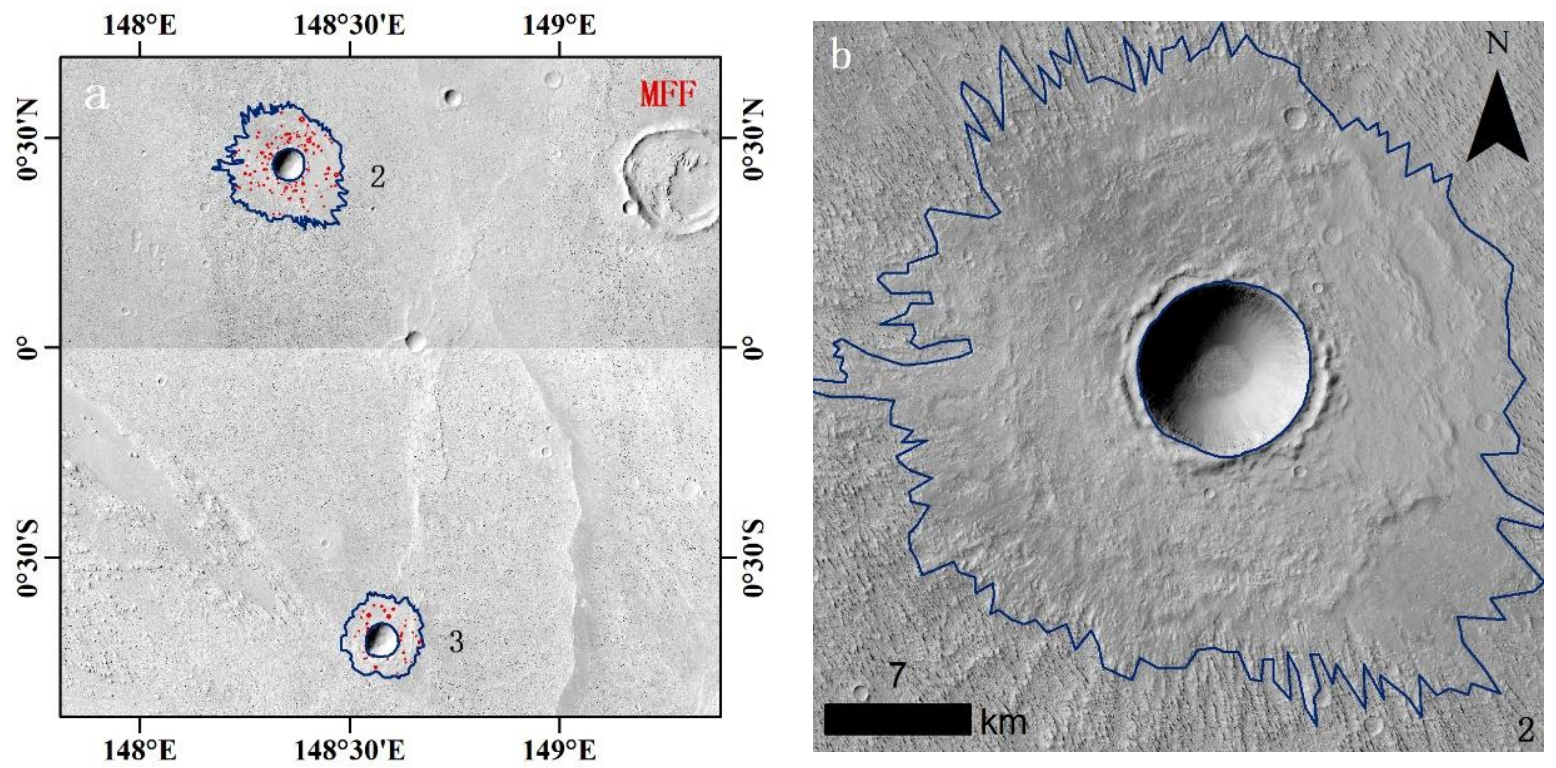

Figure 1. The spatial relationship between yardangs and layered ejecta craters. (a) Two layered ejecta craters in the Medusae Fossae Formation (MFF); (b) one typical layered ejecta crater superposed on yardangs. The background is a Context Camera (CTX) mosaic (5 m/pixel).

\section{Study Region and Data Sets}

The MFF (Figure 2) is considered to be one of the youngest deposits on the Martian surface $[46,47]$, which stretches between $170^{\circ} \mathrm{E}-240^{\circ} \mathrm{E}$ and $120^{\circ} \mathrm{W}-190^{\circ} \mathrm{W}$ in the Amazonis Planitia region and lies between the Tharsis and Elysium volcanic centers [46] and is demonstrably of Amazonian age [11,32]. Figure 2 shows the location and the yardangs in the MFF.

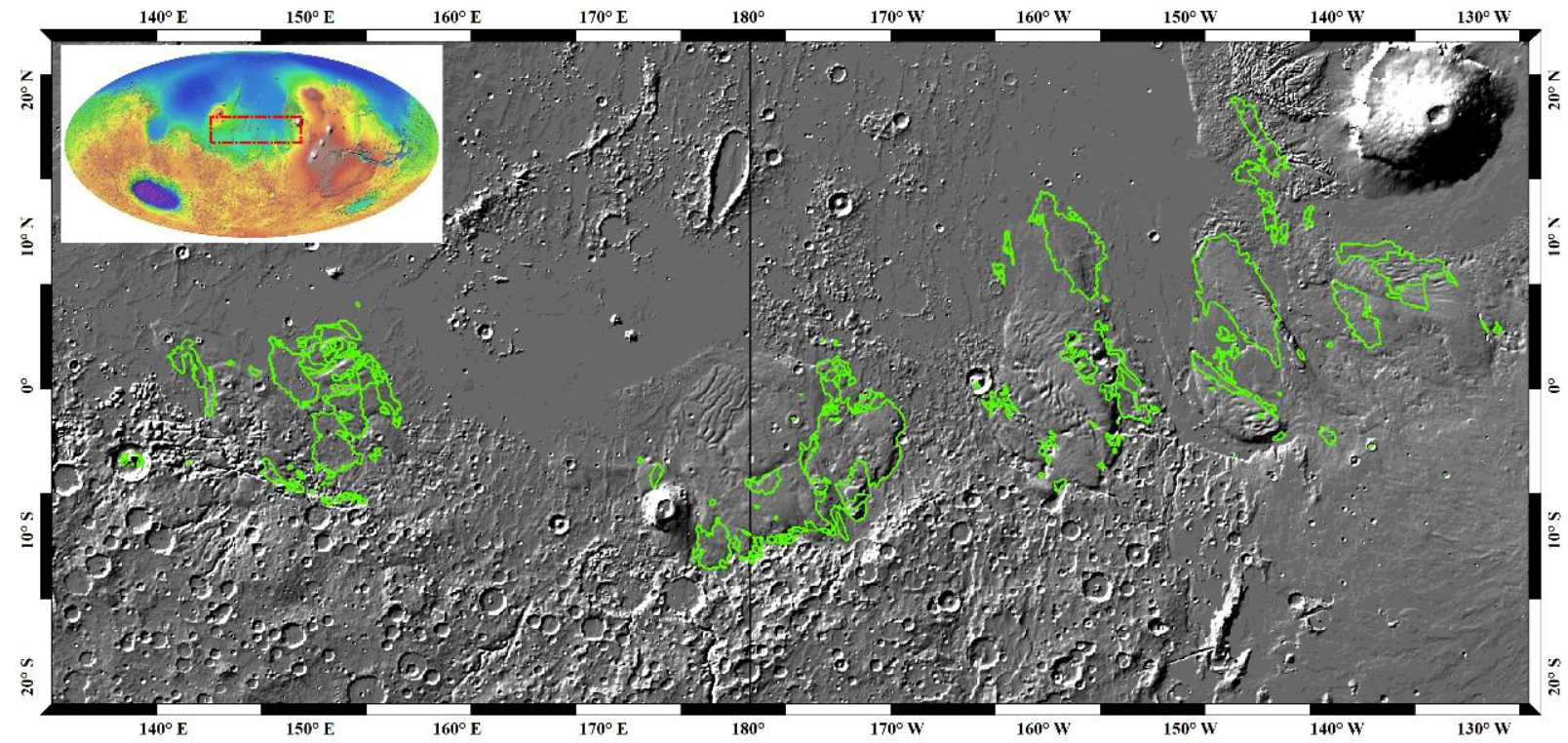

Figure 2. The yardangs in the MFF. The background is a MOLA hillshade relief map (128 pixels/degree). The green polygons are the yardang fields in the MFF [7].

The data sets used in this work were acquired by the Context Camera (CTX) onboard the Mars Reconnaissance Orbiter [36,48]. Recently, the Bruce Murray Laboratory for Planetary Visualization has produced a global mosaic of Mars with the resolution of $5 \mathrm{~m}$ / pixel using CTX images [49]. The CTX mosaic covered 97.3\% of Mars's surface and 
was subdivided into $2^{\circ} \times 2^{\circ}$ and $4^{\circ} \times 4^{\circ}$ tiles, which can be obtained from the website of http:/ / murray-lab.caltech.edu/CTX/ (accessed on 1 January 2021). In this research, a total of 72 tiles of $2^{\circ} \times 2^{\circ} \mathrm{CTX}$ mosaic were used to identify the yardangs and to map the layered ejecta and the craters superposed.

\section{Method}

Based on our previous yardang mapping in the MFF [7], we first visually identify the layered ejecta craters that are superposed on the yardangs. Then, the areas of the layered ejecta are mapped and used as the counting areas in CFSD. The ages of the layered ejecta are thus derived according to the crater size-frequency, and they are considered as the lower limits by which the corresponding yardangs' development had been ceased. The main method flow is shown in the Figure 3.

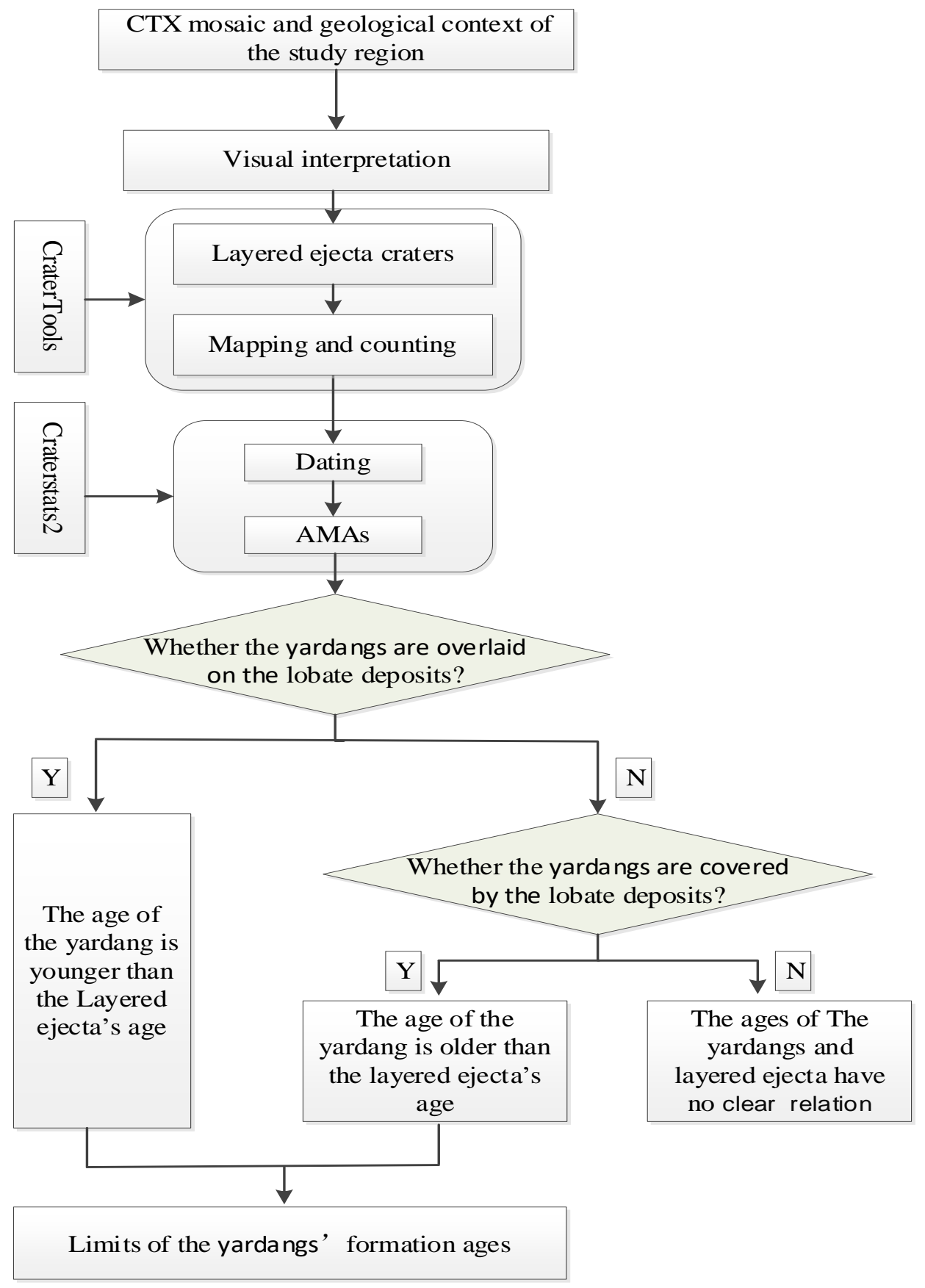

Figure 3. Flowchart of the process for constraining the yardangs formation age. 


\subsection{Layered Ejecta Mapping}

The layered ejecta were mapped on the CTX mosaic in this area. In the process, the layered ejecta were first identified by visual interpretation, and great attention was paid to check if the yardangs were in coexistence. Then, the intersection relations between the layered ejecta and yardangs were determined, and only the layered ejecta that overlay on the yardangs were selected for dating. The boundaries of the ejecta were carefully analyzed, and they were screened out if their boundaries sharply contacted the surroundings because this implies that the ejecta had probably been altered by the yardangs. Finally, only the layered ejecta on the yardangs that were completely preserved were used for dating and constraining the age of the overlaid yardangs.

The boundaries of the layered ejecta were mapped in the Environmental Systems Research Institute's ArcGIS platform with the extension CraterTools [50]. The inner boundaries of the layered ejecta, i.e., the rim of the corresponding crater, were also mapped. The area between the inner and outer boundary of the layered ejecta was used for age dating of the layered ejecta. The area can be determined by CraterTools independent of the map projection [50].

\subsection{Crater Counting in Layered Ejecta}

In this research, CraterTools was again used for mapping and measuring craters superposed on the layered ejecta. In CraterTools, three points along the crater rim were identified and were used to fit the circle representing the crater. Yue et al. (2019) [51] indicated that the fitting errors would be minimized if the three points are evenly distributed along the crater rim, and their strategy is adopted in the research. In addition, we were always cautious of those craters in chains or clusters with irregular shapes because they are probably secondary craters and should be excluded in the dating process (e.g., [52,53]). Additionally, we analyzed spatial randomness and clustering of the mapped craters superimposed on each measurement area with the method of mean closest two neighbors' distance (MC2ND) and standard deviation of adjacent area (SDAA). The measurement of MC2ND is more successful in identifying the cluster and placing this crater arrangement in the 8th percentile, over $2 \sigma$ below the mean value. The SDAA method intuitively corresponds to what we expect to see of a random distribution. Its core concept is if you take a surface with $n$ craters and divide it into $n$ equally sized patches, you would expect to see roughly one crater per patch. The adjacent area is the converse of this: for each crater, we find the patch for which every point is closer to it than to any other crater and then examine the distribution of patch sizes [23].

\subsection{AMAs of the Layered Ejecta and Constraint of Yardangs' Age}

Craterstats2 software (https:/ / www.geo.fu-berlin.de/en/geol/) (accessed on 1 January 2021) was used to derive the AMAs of the layered ejecta. This software has assembled almost all the existing chronology and production functions for Mars, and it has been widely used in Mars surface dating (e.g., [53]). In this process, the Martian chronology system of Neukum-Ivanov $(2001$; see $[18,29,51])$ and the production function by Ivanov (2001) were used. The AMAs of the layered ejecta were derived with the Poisson fitting [24], which expresses the result as a likelihood function through Poisson statistics, and Bayesian inference and the resulting uncertainty is independent of the grouping of the crater size-frequency distribution.

Since the layered ejecta are superposed on the yardangs, the yardangs' development must have ceased by the time that the corresponding layered ejecta occurred. Thus, the AMAs of the layered ejecta are the lower limits of the yardangs' ages regardless of the duration they have experienced. In addition, it is necessary to point out that the aeolian process is still pervasive on the Martian surface, so the lower limits of the yardangs' ages refer to the time of the termination of extensive formation. 


\section{Results}

Figure 4 shows all of the yardangs and all of the layered ejecta craters nearby in the Medusae Fossae Formation. There are 24 layered ejecta craters in this region; however, only six of them are superposed on the yardangs and are not altered at all by them. Therefore, we mapped the continuous ejecta of the six layered ejecta craters as the counting areas. All the craters superposed on the layered ejecta were mapped, and their diameters were measured.

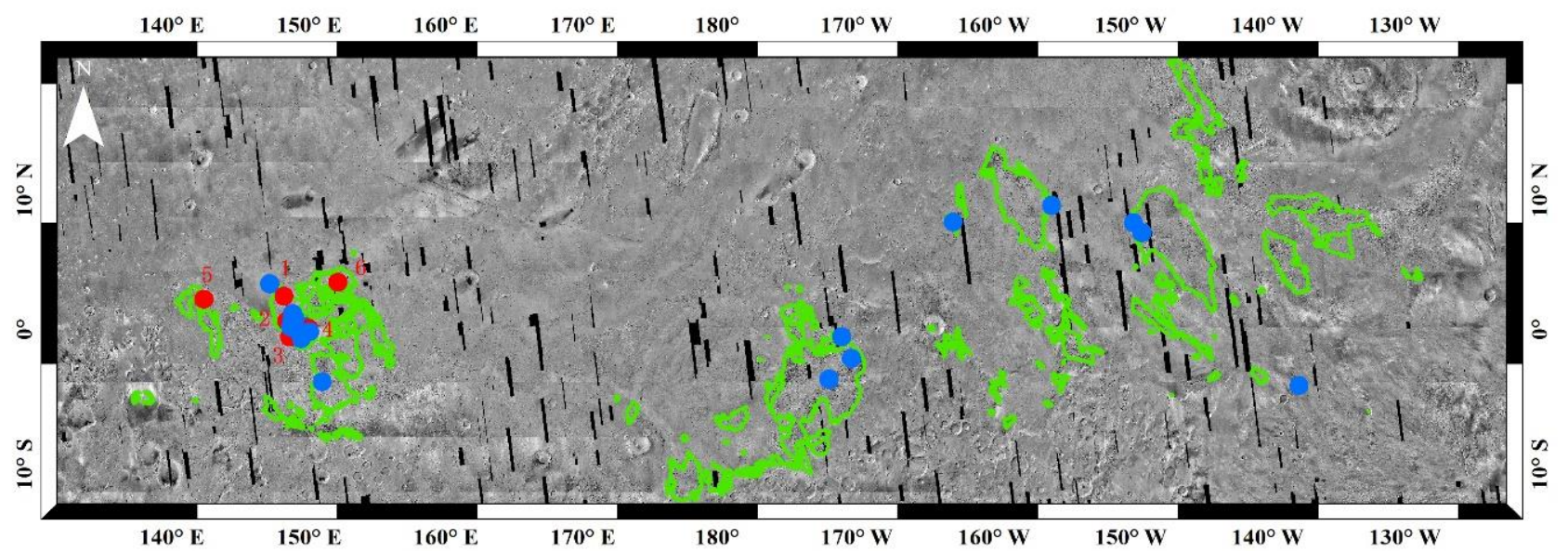

Figure 4. Yardangs (green polygons) in the MFF and the layered ejecta craters (circle points) nearby. Among the 24 layered ejecta craters, only six (red circle points) are selected for dating because their continuous ejecta is not altered by the surrounding yardangs. The yardangs' locations are from Liu et al. (2020). The image is a CTX mosaic at a resolution of $5 \mathrm{~m} /$ pixel.

Figure 5 shows the distribution of the six layered ejecta and AMAs. Figure 6 shows the details of the six layered ejecta and the corresponding dating results. The area of each layered ejecta has two boundaries- the inner boundary is roughly along the crater rim, while the outer boundary delineates the distinct termination of the continuous ejecta. Figure 6 clearly indicates that the layered ejecta is not altered by the surrounding yardangs, and some yardangs are covered by the lobate deposits, which indicates that yardangs have a clear relative age relation with the layered ejecta craters. Additionally, the mapped craters in the ejecta are not contaminated by the yardangs at all. Figure 6 also includes the corresponding dating results for each layered ejecta, and the crater diameter range for the dating result is shown in red. The analysis results of spatial randomness and clustering of the mapped craters are on the top of each CFSD fitting curve. It is clear that for the crater diameters used for dating, each of the MC2ND of the mapped craters falls within $\pm 3 \sigma$ of the expectation value derived from Monte Carlo simulation, indicating the spatial distribution of the mapped craters is random. 


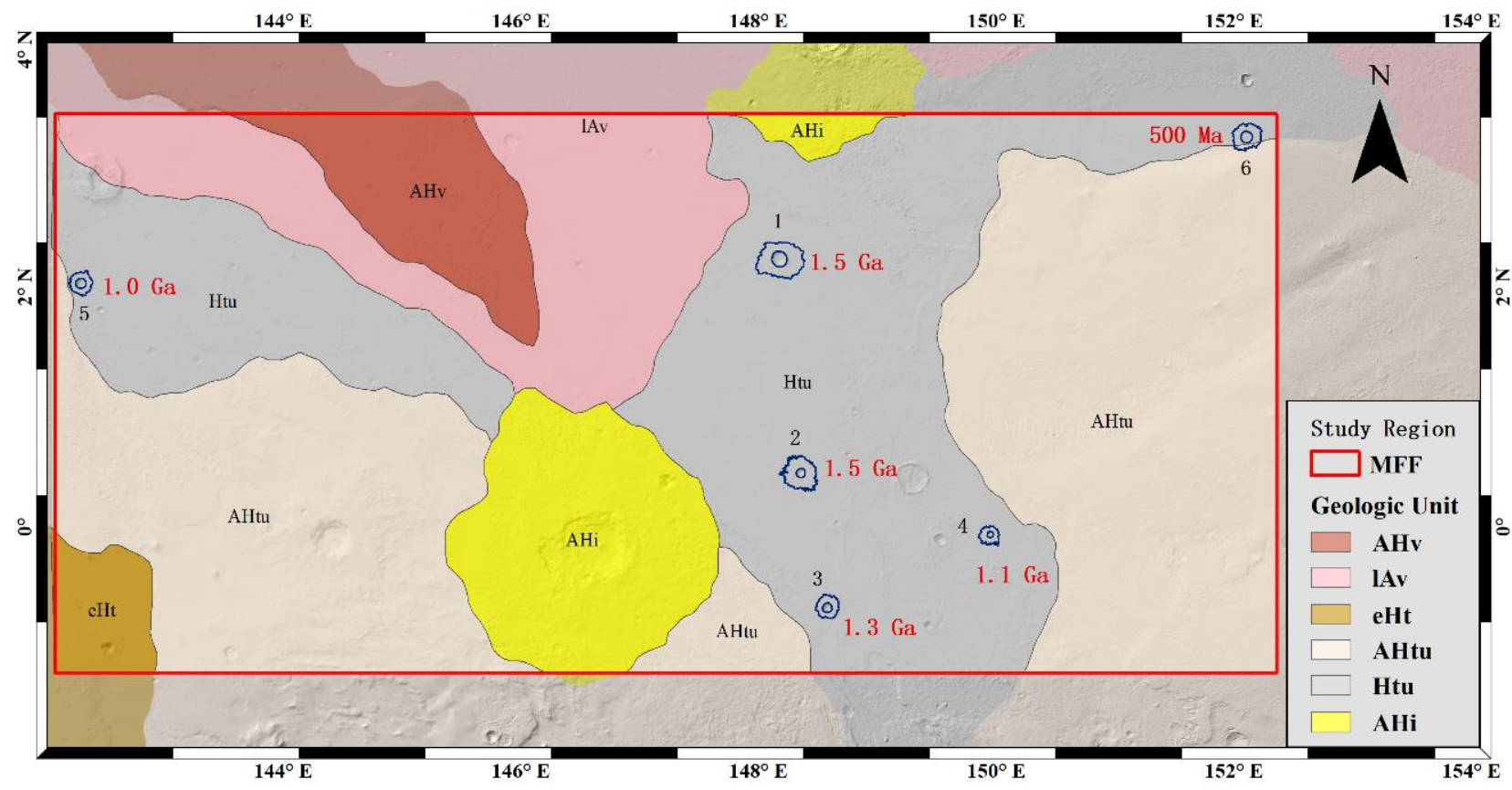

Figure 5. Distribution of layered ejecta craters and the absolute model age (AMA). The base map is the geological map [11] overlaid on the Mars Orbiter Laser Altimeter (MOLA) hillshade relief map. The red rectangle is about $607 \mathrm{~m}$ from east to west and $273 \mathrm{~m}$ from north to south.
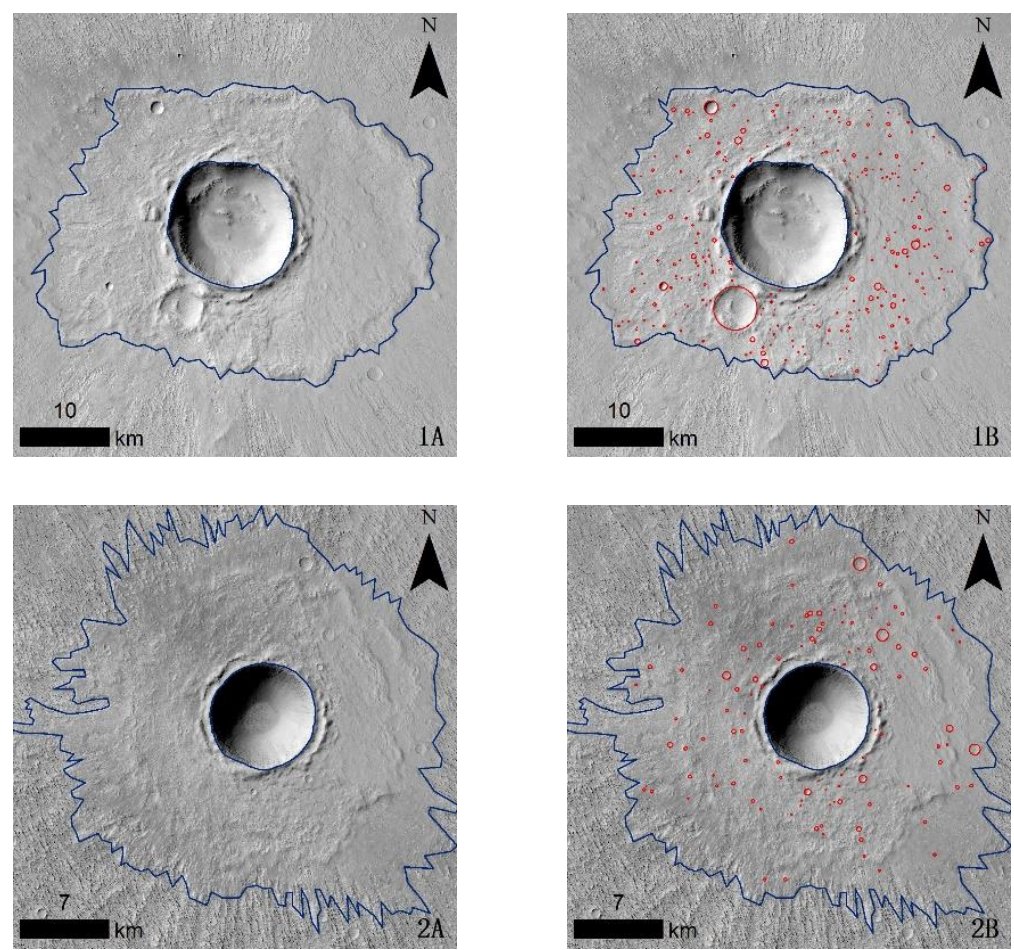

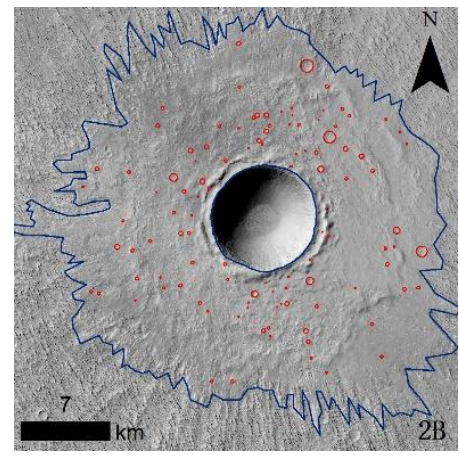

Figure 6. Cont.
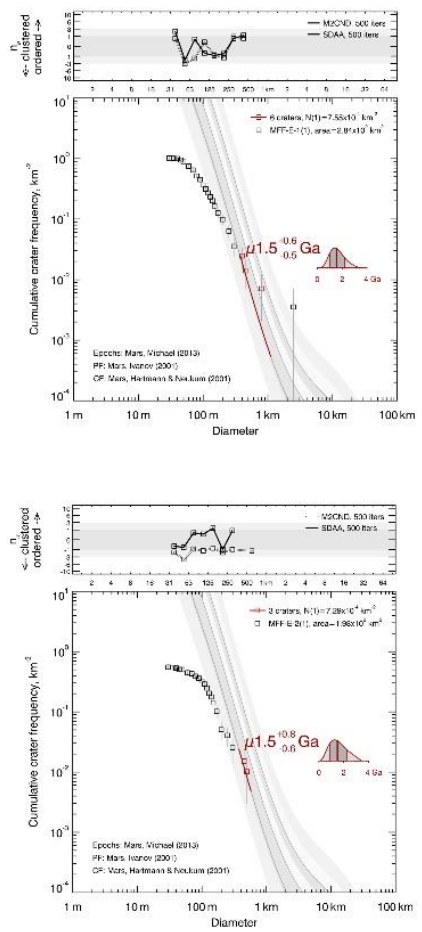

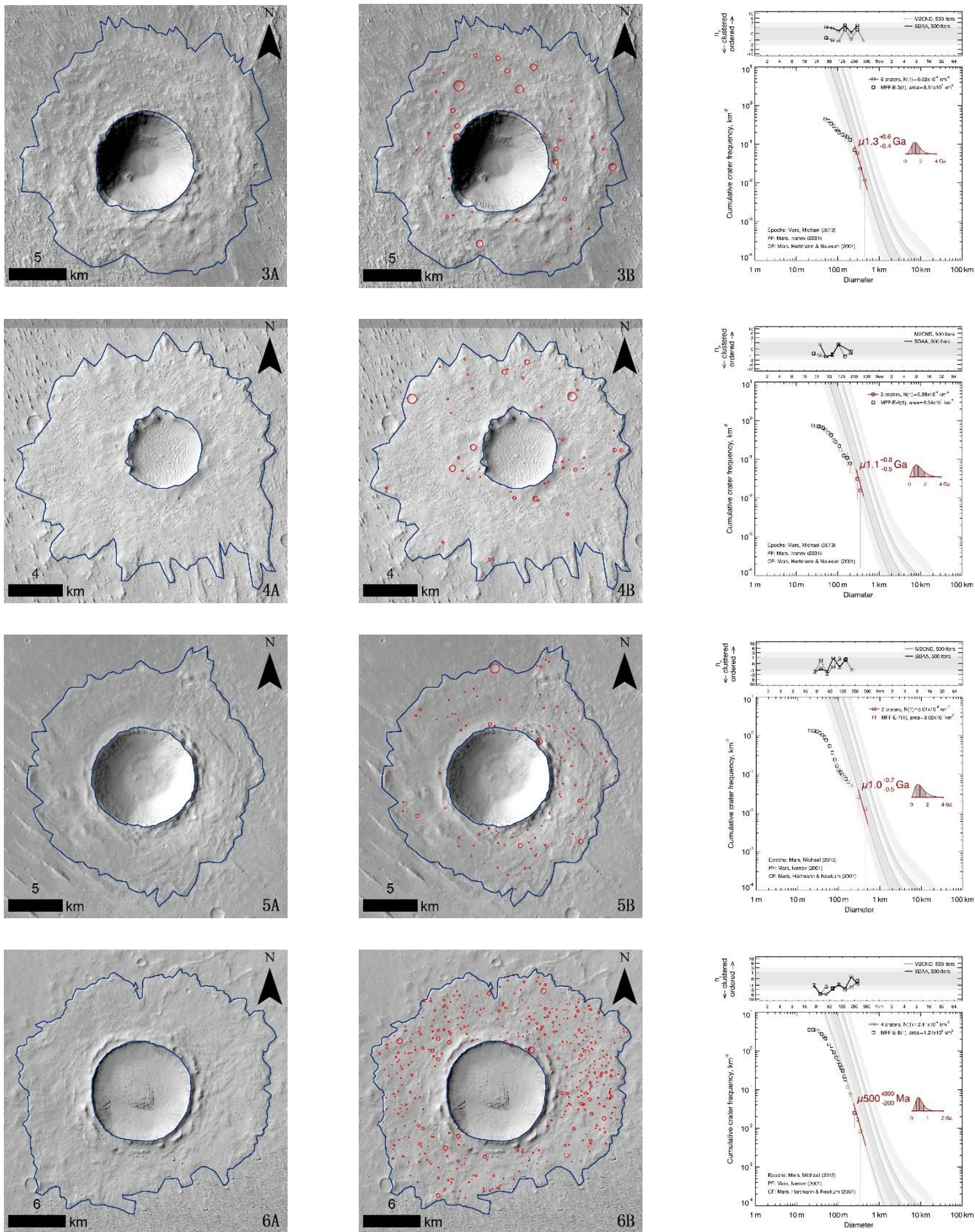

Figure 6. Layered ejecta, craters on the ejecta, and dating results in the MFF. There are six layered ejecta selected after rigorous evaluation that are definitely formed after the development of corresponding yardangs had been ceased. Layered ejecta labeled from $1 \mathrm{~A}$ to $6 \mathrm{~A}$ are the primary image, and $1 \mathrm{~B}$ to $6 \mathrm{~B}$ are corresponding to the layered ejecta in Figures 3

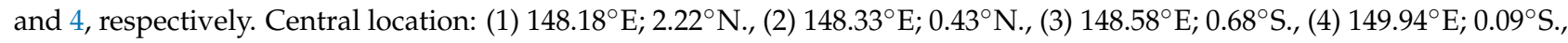
(5) $142.30^{\circ} \mathrm{E} ; 2.03^{\circ} \mathrm{N} .,(6) 152.11^{\circ} \mathrm{E} ; 3.26^{\circ} \mathrm{N}$. The Martian chronology system is Neukum-Ivanov $(2001$; see $[18,29,53])$, and the production function is from Ivanov (2001).

As the dating results show in Table 1, each AMA has a label of $\pm \sigma$. Since the dating method is based on a crater chronology model with Poisson statistics and Bayesian infer- 
ence, the result can be expressed as a likelihood function with an intrinsic uncertainty. Even in the case of no crater at all, a meaningful likelihood function can also be obtained [22]. For the Neukum chronology function, to make an analogous representation based on percentiles, these are more directly interpretable in a probabilistic treatment, rather than mean and standard deviation. Thus, the $\pm \sigma$ points are placed on $\pm 34 \%$ of either side of the median so as to include $68 \%$ of the Probability Density Function (PDF), by analogy to a normal distribution [24]. Meanwhile, Table 1 further lists the detailed information in the dating process, including the counting areas ranging from $138 \mathrm{~km}^{2}$ to $267 \mathrm{~km}^{2}$, the minimum crater diameter for dating is $250 \mathrm{~m}$, and the crater number ranging from 38 to 424. The ages of the layered ejecta range from $\sim 0.50 \mathrm{Ga}$ to $\sim 1.5 \mathrm{Ga}$, indicating that the development of the yardangs had been ceased at least before the corresponding ages.

Table 1. Dating results of layered ejecta in the MFF. The numbers (No.) correspond to those in Figures 4 and 5. The fitting diameter range refers to those fitting with the chronology curve, and the sampled craters are the numbers of all the mapped craters in each layered ejecta.

\begin{tabular}{ccccc}
\hline No. & Area $\left(\mathbf{k m}^{\mathbf{2}}\right)$ & Fitting Diameter Range $\mathbf{( m )}$ & Sampled Craters & Dating Result \\
\hline 1 & 284 & $380-1100$ & 289 & $1.5_{-0.5}^{+0.6} \mathrm{Ga}$ \\
2 & 198 & $380-570$ & 109 & $1.5_{-0.6}^{+0.8} \mathrm{Ga}$ \\
3 & 85.1 & $260-510$ & 38 & $1.3_{-0.4}^{+0.6} \mathrm{Ga}$ \\
4 & 63.4 & $280-420$ & 48 & $1.1_{-0.5}^{+0.8} \mathrm{Ga}$ \\
5 & 80.2 & $300-510$ & 108 & $1.0_{-0.5}^{+0.7} \mathrm{Ga}$ \\
6 & 121 & $240-460$ & 424 & $500_{-200}^{+300} \mathrm{Ma}$ \\
\hline
\end{tabular}

\section{Discussion}

\subsection{Yardangs' Development in the MFF}

Yardangs are typical wind-eroded landforms, and their development includes the embryonic, adolescent, mature, and recession stages [16]. In the recession stage, continuous erosion causes the long yardang ridges to become dissected into isolated mounds and the tops of the yardangs to narrow further and decrease in height until they finally disappear [16]. Therefore, provided continuous wind erosion, yardangs keep active until disappearance, and this activity will inevitably alter the landforms superposed, such as the layered ejecta. Yardangs in the MFF occupy $~ 562,640 \mathrm{~km}^{2}$, accounting for $\sim 86.51 \%$ of the Martian yardangs between $30^{\circ} \mathrm{N}$ and $30^{\circ} \mathrm{S}$ [7], and most yardangs there seem in the adolescent or mature stage (Figure 7). However, there are only six unaltered layered ejecta identified in this region, indicating most of the yardangs in this area were still active when the layered ejecta craters occurred.

This observation is consistent with the Martian current climate. Mars has been a cold and dry planet, and its surface has been dominated by aeolian activity for a long time. However, in Mars's much earlier history, a very different climate may have existed [10,54]. Obviously, this climate condition is favorable for the development of yardangs. In addition, planetary climatological studies reveal that a perennial Hadley cell drives significant meridional circulations in the atmosphere on Mars [13,55], and the wind is strongest around the equator near the surface of Mars [13]. The rarity of the unaltered layered ejecta identified in this area is consistent with these studies. 


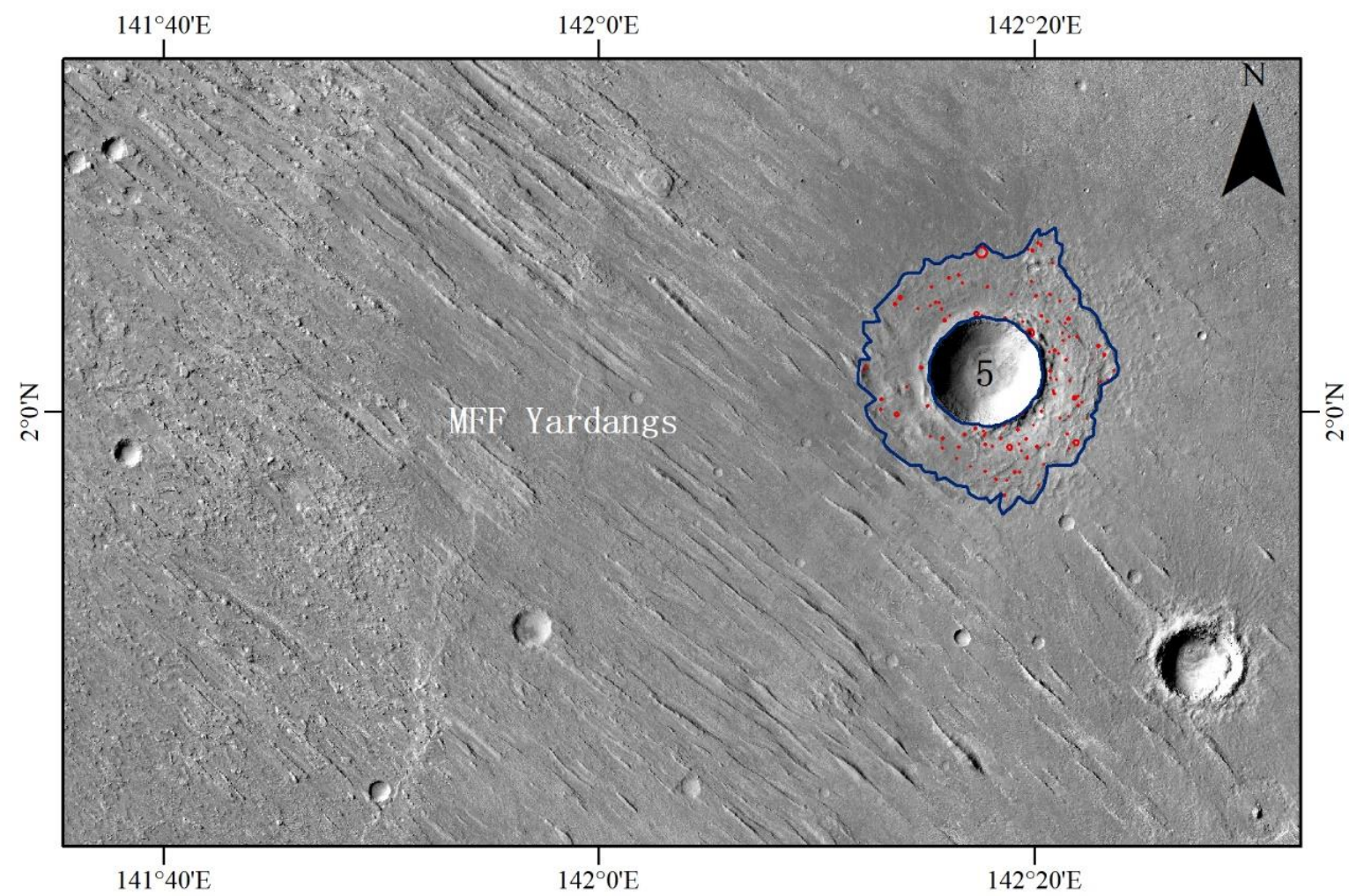

Figure 7. Yardangs' morphology in the MFF. The yardangs have a long ridge shape, and their peaks are smooth, indicating that these yardangs are in the adolescent or mature stage.

The six unaltered layered ejecta on the yardangs may indicate that the climate conditions changed in these areas, and then the yardangs ceased development. The reasons for this alteration are currently unknown. This alteration must have occurred before the appearance of these layered ejecta, i.e., before $\sim 0.50-\sim 1.5 \mathrm{Ga}$, which provides valuable information for studies of the Martian paleoclimate.

\subsection{Yardangs Overlaid on the Layered Ejecta}

Figure 8 shows three layered ejecta where yardangs are overlaid on the ejecta blanket. A, B, and C layered ejecta craters are in the Elysium Planitia of the MFF. Layered ejecta $\mathrm{A}$ is on the surrounding yardangs, which are more than a hundred meters in length and several hundred meters in height. The boundaries of the ejecta are obviously altered by the yardangs, indicated by the sharp contact between them. Similar contact relationships are found for layered ejecta $B$ and $C$ and other yardangs that we mentioned above, indicating that the yardangs are still active when the layered ejecta craters are formed.

The ages of these layered ejecta are difficult to determine by the CFSD method, as we have expressed; however, the superposed crater size-frequency distribution still provides some information on the development of the yardangs. The largest craters may be preserved from the alteration of the surrounding yardangs, or some of them were removed in the development of yardangs. Therefore, the ages from the group of the largest craters indicate that the yardangs were still active at least by that time. The dating results of the layered ejecta in Figure 8 were from $\sim 0.11 \mathrm{Ga}$ to $\sim 2.0 \mathrm{Ga}$, so the yardangs must be active by these ages and may continue to be today. This speculation is consistent with the fact that the Hadley cell still dominates in the Martian surface [7,13]. 

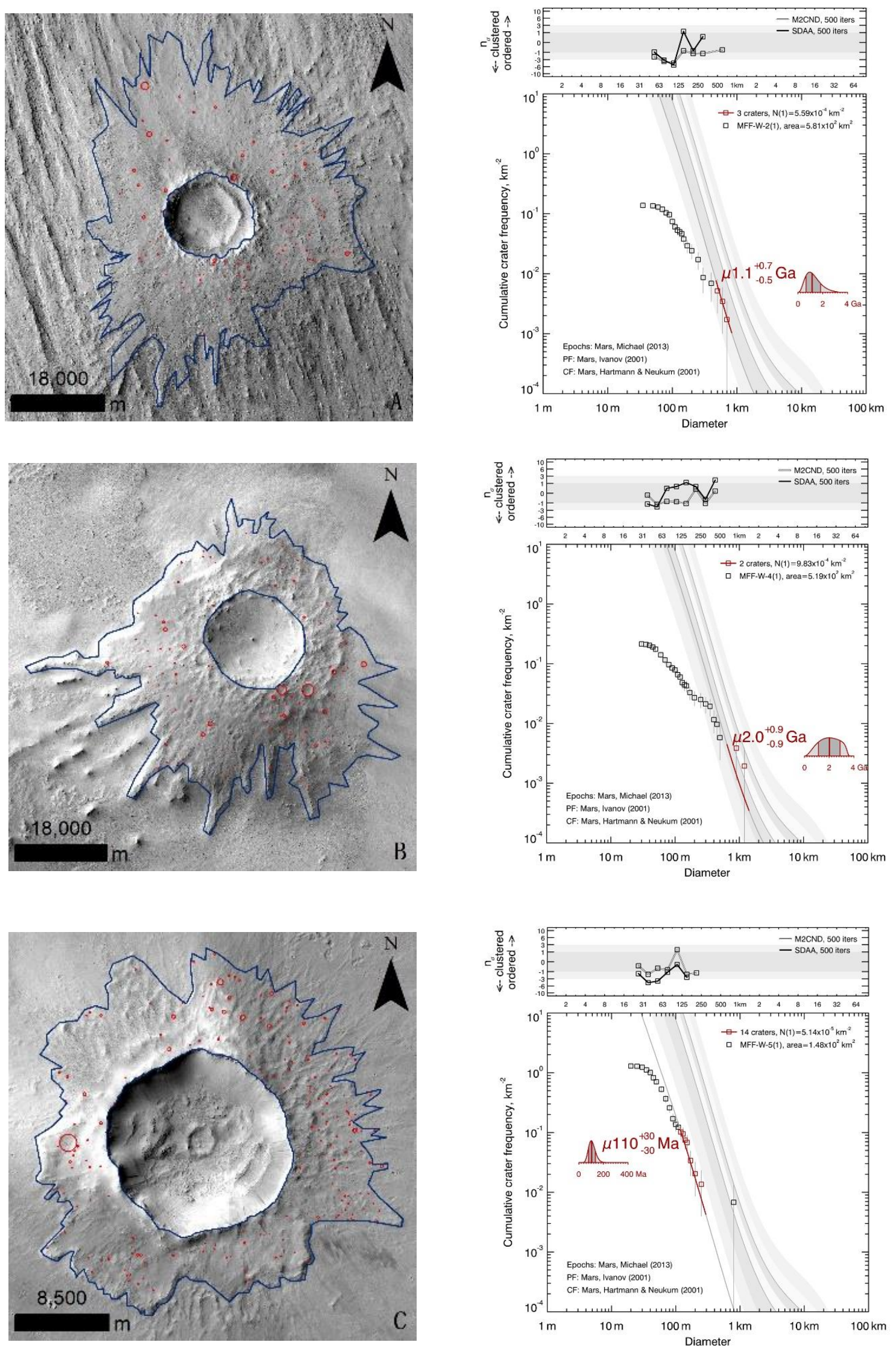

Figure 8. Dating results of layered ejecta for three layered ejecta craters with the largest group craters, and the layered ejecta have been altered by yardangs. A, B, and C are distributed in the Elysium Planitia. 
This analysis is also consistent with the distribution of the craters in the MFF. Figure 9 shows that there are far fewer impact craters in the yardang areas, indicating that some impact craters have been removed by the yardangs. Therefore, most yardangs in the MFF may have been active in recent history, although the climate conditions changed for some currently unknown reasons, and the yardangs' development has ceased in some areas.

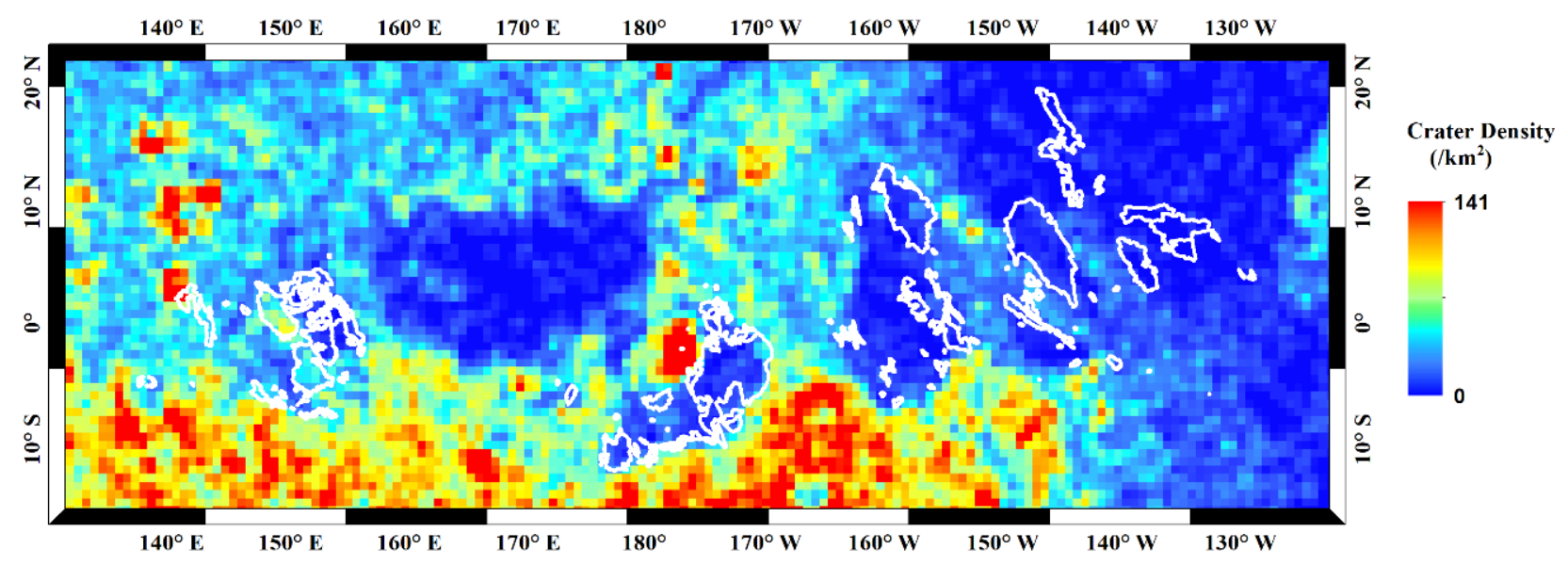

Figure 9. The density of impact craters larger than $1 \mathrm{~km}$ in diameter in the MFF. It can be seen that the craters in yardangs' area are indeed more sparsely distributed than in the other areas. The impact craters are from reference [44].

\section{Conclusions}

In this study, we analyzed the development of the Martian yardangs in the MFF. An indirect method by dating the ages of the superposed layered ejecta was used to constrain the development process of yardangs. Based on the mapping of yardangs in this area, 24 layered ejecta craters were identified within or nearby the yardangs. Through rigorous checking, only six layered ejecta craters were found completely unaltered by the yardangs, and thus they must have been formed after the yardangs' development had ceased. The small fraction of this unaltered layered ejecta indicates that most of the yardangs are active in recent Martian history. In addition, with the layered ejecta of the six craters as counting areas, their ages were obtained with the CFSD method. The results show that the ages of the six layered ejecta range from $\sim 0.50 \mathrm{Ga}$ to $\sim 1.5 \mathrm{Ga}$, indicating that the evolution of the corresponding yardangs had ceased before this time. The dating results in this research provide temporal information for studying Martian yardangs' development.

Author Contributions: Data curation, J.L. and S.N.; Formal analysis, J.L., Z.Y. and K.D.; Methodology, J.L., Z.Y., K.D. and S.G.; Supervision, Z.Y.; Writing—original draft, J.L., Z.Y. and K.D.; Writing-review \& editing, J.L., Z.Y., K.D. and S.G. All authors have read and agreed to the published version of the manuscript.

Funding: This work was supported by the Strategic Priority Research Program of Chinese Academy of Sciences (grant No. XDB41000000) and the Science and Technology Development Fund of Macau (Grant No. 131/2017/A3).

Data Availability Statement: Not applicable.

Acknowledgments: The authors gratefully acknowledge the NASA/Malin Space Science Systems and the Bruce Murray Laboratory for Planetary Visualization for making the CTX data and CTX mosaics available. The authors also thank Thomas Kneissl for the software CraterTools and Gregory Michael for the software of Craterstats2.

Conflicts of Interest: The authors declare no conflict of interest. 


\section{References}

1. McCauley, J.F. Mariner 9 evidence for wind erosion in the equatorial and mid-latitude regions of Mars. J. Geophys. Res. 1973, 78, 4123-4137. [CrossRef]

2. Carr, M.H.; Crumpler, L.S.; Cutts, J.A.; Greeley, R.; Guest, J.E.; Masursky, H. Martian impact craters and emplacement of ejecta by surface flow. J. Geophys. Res. 1977, 82, 4055-4065. [CrossRef]

3. Ward, A.W. Yardangs on Mars: Evidence of recent wind erosion. J. Geophys. Res. 1979, 84, 8147. [CrossRef]

4. Bridges, N.T.; Calef, F.J.; Hallet, B.; Herkenhoff, K.E.; Lanza, N.L.; Le Mouélic, S.; Newman, C.E.; Blaney, D.L.; De Pablo, M.A.; Kocurek, G.A.; et al. The rock abrasion record at Gale Crater: Mars Science Laboratory results from Bradbury Landing to Rocknest. J. Geophys. Res. Planets 2014, 119, 1374-1389. [CrossRef]

5. Ding, Z.; Zhao, J.; Wang, J.; Lai, Z. Yardangs on Earth and implications to Mars: A review. Geomorphology 2020, $364,107230$. [CrossRef]

6. Runyon, K.D.; Viviano, C.E.; Day, M. Abraded pyroclastic linear paleodunes in Syria and Daedalia Plana, Mars. Earth Planet. Sci. Lett. 2021, 557, 116719. [CrossRef]

7. Liu, J.; Di, K.; Gou, S.; Yue, Z.; Liu, B.; Xiao, J.; Liu, Z. Mapping and spatial statistical analysis of Mars Yardangs. Planet. Space Sci. 2020, 192, 105035. [CrossRef]

8. Ward, A.W.; Greeley, R. Evolution of the yardangs at Rogers Lake, California. Geol. Soc. Am. Bull. 1984, 95, 829. [CrossRef]

9. Barlow, N.G. Constraints on early events in Martian history as derived from the cratering record. J. Geophys. Res. 1990, 95, 14191. [CrossRef]

10. Barlow, N.G. Mars: An Introduction to Its Interior, Surface and Atmosphere; Cambridge University Press: Cambridge, UK, 2008; pp. 146-147.

11. Tanaka, K.L.; Skinner, J.A.; Dohm, J.M.; Irwin, R.P.; Kolb, E.J.; Fortezzo, C.M.; Platz, T.; Michael, G.G.; Hare, T.M. Geologic map of Mars; United States Geological Survey: Menlo Park, CA, USA, 2014.

12. Barchyn Thomas, E. Modeling the mechanisms behind yardang evolution. J. Geophys. Res. Earth Surf. Earth Surf. 2018, 123, 618-621. [CrossRef]

13. Xiao, J.; Chow, K.C.; Chan, K. Dynamical processes of dust lifting in the northern mid-latitude region of Mars during the dust storm season. Icarus 2019, 317, 94-103. [CrossRef]

14. Urso, A.; Chojnacki, M.; Vaz, D.A. Dune-Yardang Interactions in Becquerel Crater, Mars. J. Geophys. Res. Planets 2018, 123, 353-368. [CrossRef] [PubMed]

15. Qu, J.; Niu, Q.; Gao, D. Formation and Development Processes Pattern of Dunhuang Yardang Landforms; Geological Publishing House: Beijing, China, 2014.

16. Dong, Z.; Lv, P.; Lu, J.; Qian, G.; Zhang, Z.; Luo, W. Geomorphology and origin of yardangs in the kumtagh desert, northwest China. Geomorphology 2012, 139-140, 145-154. [CrossRef]

17. Niu, Q.; Qu, J.; Liu, B.; Qian, G.; Zhang, Z.; Luo, W. Dating methods for chronological study of yardang landforms: A review and perspective in application. Mar. Geol. Quat. Geol. 2013, 33, 201. [CrossRef]

18. Neukum, G. Meteorite Bombardment and Dating of Planetary Surfaces; NASA: Washington, DC, USA, 1984.

19. Barlow, N.G.; Bradley, T.L. Martian impact craters: Correlations of ejecta and interior morphologies with diameter, latitude, and terrain. Icarus 1990, 87, 156-179. [CrossRef]

20. Hiesinger, H.; Jaumann RNeukum, G.; Head, J.W. Ages of mare basalts on the lunar nearside. J. Geophys. Res. Planets 2000, 105, 29239-29275. [CrossRef]

21. Hiesinger, H. Ages and stratigraphy of mare basalts in Oceanus Procellarum, Mare Nubium, Mare Cognitum, and Mare Insularum. J. Geophys. Res. 2003, 108, 1. [CrossRef]

22. Michael, G.G.; Neukum, G. Planetary surface dating from crater size-frequency distribution measurements: Partial resurfacing events and statistical age uncertainty. Earth Planet. Sci. Lett. 2010, 294, 223-229. [CrossRef]

23. Michael, G.G.; Platz, T.; Kneissl, T.; Schmedemann, N. Planetary surface dating from crater size-frequency distribution measurements: Spatial randomness and clustering. Icarus 2012, 218, 169-177. [CrossRef]

24. Michael, G.G.; Kneissl, T.; Neesemann, A. Planetary surface dating from crater size-frequency distribution measurements: Poisson timing analysis. Icarus 2016, 277, 279-285. [CrossRef]

25. Hiesinger, H.; Bernhardt, H.; Reiss, D.; Tirsch, D.; Ralf, J.; Ernst, H.; Head, J.W.; Michael, G.; Williams, D.A.; Bishop, J.L.; et al. Absolute Model Ages and Stratigraphy of Neukum Crater Geologic Units. In Proceedings of the Lunar \& Planetary Science Conference, The Woodlands, TX, USA, 19-23 March 2018.

26. Jia, M.; Yue, Z.; Di, K.; Liu, B.; Liu, J.; Michael, G. A catalogue of impact craters larger than $200 \mathrm{~m}$ and surface age analysis in the Chang'e-5 landing area. Earth Planet. Sci. Lett. 2020, 541, 116272. [CrossRef]

27. Stöffler, D.; Ryder, G. Stratigraphy and isotope ages of lunar geologic units: Chronological standard for the inner solar system. Space Sci. Rev 2001, 96, 9-54. [CrossRef]

28. Ivanov, B.A. Mars/Moon Cratering Rate Ratio Estimates. Space Sci. Rev. 2001, 96, 87-104. [CrossRef]

29. Hartmann, W.K.; Neukum, G. Cratering chronology and the evolution of mars. Space Sci. Rev. 2001, 96, 165-194. [CrossRef]

30. Neukum, G.; Ivanov, B.A.; Hartmann, W.K. Cratering Records in the Inner Solar System in Relation to the Lunar Reference System. Space Sci. Rev. 2001, 96, 55-86. [CrossRef]

31. Hartmann, W.K. Martian Cratering 8: Isochron Refinement and the Chronology of Mars. Icarus 2005, 174, 294-320. [CrossRef] 
32. Tanaka, K.L. The stratigraphy of Mars. J. Geophys. Res. Solid Earth 1986, 91, E139-E158. [CrossRef]

33. Page, D.P.; Balme, M.R.; Grady, M.M. Dating Martian climate change. Icarus 2009, 203, 376-389. [CrossRef]

34. Werner, S.C.; Tanaka, K.L. Redefinition of the crater-density and absolute-age boundaries for the chronostratigraphic system of Mars. Icarus 2011, 215, 603-607. [CrossRef]

35. Christensen, P.R.; Jakosky, B.M.; Kieffer, H.H.; Malin, M.C.; McSween, J.H.Y.; Nealson, K.; Mehall, G.L.; Silverman, S.H.; Ferry, S.; Caplinger, M.; et al. The Thermal Emission Imaging System (THEMIS) for the Mars 2001 Odyssey Mission. Space Sci. Rev. 2004, 110, 85-130. [CrossRef]

36. Malin, M.C.; Bell, J.F.; Cantor, B.A.; Caplinger, M.A.; Calvin, W.M.; Clancy, R.T.; Edgett, K.S.; Edwards, L.; Haberle, R.M.; James, P.B.; et al. Context Camera Investigation on board the Mars Reconnaissance Orbiter. J. Geophys. Res. 2007, 112, E5. [CrossRef]

37. McEwen, A.S.; Eliason, E.M.; Bergstrom, J.W.; Bridges, N.T.; Hansen, C.J.; Delamere, W.A.; Grant, J.A.; Gulick, V.C.; Herkenhoff, K.E.; Keszthelyi, L.; et al. Mars Reconnaissance Orbiter's High Resolution Imaging Science Experiment (HiRISE). J. Geophys. Res. 2007, 112, E5. [CrossRef]

38. Barnouin, O.S.; Zuber, M.T.; Smith, D.E.; Neumann, G.A.; Herrick, R.R.; Chappelow, J.E.; Murchie, S.L.; Prockter, L.M. The morphology of craters on Mercury: Results from MESSENGER flybys. Icarus 2012, 219, 414-427. [CrossRef]

39. Li, L.; Yue, Z.; Di, K.; Peng, M. Observations of Martian layered ejecta craters and constraints on their formation mechanisms. Meteorit. Planet. Sci. 2015, 50, 508-522. [CrossRef]

40. Mouginis-Mark, P. Martian fluidized crater morphology: Variations with crater size, latitude, altitude, and target material. J. Geophys. Res. 1979, 84, 8011-8022. [CrossRef]

41. Wohletz, K.H.; Sheridan, M.F. Martian rampart crater ejecta: Experiments and analysis of melt-water interaction. Icarus 1983, 56, 15-37. [CrossRef]

42. Barlow, N.G.; Boyce, J.M.; Costard, F.M.; Craddock, R.A.; Sakimoto, S.E.H.; Kuzmin, R.O.; Roddy, D.J.; Soderblom, L.A.; Garvin, J.B. Standardizing the nomenclature of Martian impact crater ejecta morphologies. J. Geophys. Res. Planets 2000, 105, 26733-26738. [CrossRef]

43. Reiss, D.; van Gasselt, S.; Hauber, S.E.; Michael, G.; Jaumann, R.; Neukum, G. Ages of rampart craters in equatorial regions on Mars: Implications for the past and present distribution of ground ice. Meteorit. Planet. Sci. 2006, 41, 1437-1452. [CrossRef]

44. Robbins, S.J.; Hynek, B.M. A new global database of Mars impact craters $>1 \mathrm{~km}$ : 2. Global crater properties and regional variations of the simple-to-complex transition diameter. J. Geophys. Res. Planets 2012, 117, E6. [CrossRef]

45. Daubar, I.J.; Atwood-Stone, C.; Byrne, S.; McEwen, A.S.; Russell, P.S.; Atwood-Stone, C. The morphology of small fresh craters on Mars and the Moon. J. Geophys. Res. Planets 2014, 119, 2620-2639. [CrossRef]

46. Mandt, K.E.; Silva SL, D.; Zimbelman, J.R.; Crown, D.A. Origin of the Medusae Fossae Formation, Mars: Insights from a synoptic approach. J. Geophys. Res. Planets 2008, 113, E12. [CrossRef]

47. Neukum, G.; Basilevsky, A.T.; Kneissl, T.; Chapman, M.G.; Van Gasselt, S.; Michael, G.; Jaumann, R.; Hoffmann, H.; Lanz, J.K. The geologic evolution of Mars: Episodicity of resurfacing events and ages from cratering analysis of image data and correlation with radiometric ages of Martian meteorites-ScienceDirect. Earth Planet. Sci. Lett. 2010, 294, 204-222. [CrossRef]

48. Zurek, R.W.; Smrekar, S.E. An overview of the Mars Reconnaissance Orbiter (MRO) science mission. J. Geophys. Res. 2007, 112, E5. [CrossRef]

49. Dickson, J.; Kerber, L.; Fassett, C.; Ehlmann, B.L. A Global, Blended CTX Mosaic of Mars with Vectorized Seam Mapping: A New Mosaicking Pipeline Using Principles of Non-Destructive Image Editing. In Proceedings of the 49th Lunar and Planetary Science Conference, LPI Contribution No. 2083, id.2480, The Woodlands, TX, USA, 19-23 March 2018.

50. Kneissl, T.; van Gasselt, G.N.S. Map-projection-independent crater size-frequency determination in GIS environments-New software tool for ArcGIS. Planet. Space Sci. 2011, 59, 1243-1254. [CrossRef]

51. Michael, G.G. Planetary surface dating from crater size-frequency distribution measurements: Multiple resurfacing episodes and differential isochron fitting. Icarus 2013, 226, 885-890. [CrossRef]

52. McEwen, A.S.; Bierhaus, E.B. The importance of secondary cratering to age constraints on planetary surfaces. Annu. Rev. Earth Planet. Sci. 2006, 34, 540-567. [CrossRef]

53. Platz, T.; Michael, G.; Tanaka, K.L.; Skinner, J.A., Jr.; Fortezzo, C.M. Crater-Based Dating of Geological Units on Mars: Methods and Application for The New Global Geological Map. Icarus 2013, 225, 806-827. [CrossRef]

54. Melosh, H.J. Planetary Surface Processes; Cambridge University Press: Cambridge, UK, 2011; pp. $376-377$.

55. Mitchell, D.M.; Montabone, L.; Thomson, S.; Read, P.L. Polar vortices on Earth and Mars: A comparative study of the climatology and variability from reanalyzes. Q. J. R. Meteorol. Soc. 2015, 141, 550-562. [CrossRef] [PubMed] 